\title{
REKAYASA SLIDING SEAT PADA POMPA OBSERVASI UNTUK EFEKTIFITAS LABORATORIUM
}

\author{
Edi Widodo', Gagah Deffi Priyambudi² \\ Prodi Teknik Mesin Universitas Muhammadiyah Sidoarjo \\ Jalan Raya Gelam 250, Candi Sidoarjo 61217, Indonesia \\ E-mail : ediwidodo@umsida.ac.id ${ }^{1}$; gagahdeffi23@gmail.com²
}

\begin{abstract}
Abstrak
Salah satu yang menentukan hasil proses pembelajaran dan proses penelitian pada perkuliahan adalah kelengkapan sarana dan prasarana. Pengembangan alat pengujian dalam laboratorium diperlukan dalam mendukung kemajuan teknologi. Diantaranya adalah perancangan Sliding Seat pada alat uji pompa sentrifugal. Dua pompa yang disusun salah satunya dapat digeser dengan Sliding Seat untuk arah pergeseran sumbu x dan menggunakan ulir daya untuk memindahkan posisi dalam arah sumbu y. Untuk rekayasa Sliding Seat dalam penelitian ini di perlukan komponen pendukung yaitu : bearing (sebagai pengganti roda), ulir daya (sebagai media perpindahan posisi pompa) dan rel besi hollow (sebagai lintasan bearing). Sliding Seat ini berfungsi untuk memindahkan posisi rangkaian pompa sentrifugal yang dapat dioperasikan secara susunan seri dan paralel, dilengkapi dengan pengunci untuk menjaga kedudukan pompa agar tetap stabil ketika dioperasikan. Asumsi pompa yang digunakan sebagai objek penelitian merupakan pompa, dengan memiliki massa 80 kilogram. Hasil perancangan dan perhitungan bearing dengan kode 6203 dapat berputar sebanyak 474,5 juta putaran dengan keandalan $90 \%$ dan dibutuhkan Torsi sebesar $503 \mathrm{Nm}$ untuk memutar ulir daya dengan beban 80 kilogram atau setara dengan $784 \mathrm{~N}$, serta nilai gaya gesek statis $\left(f_{s}\right)$ yang bekerja pada rel besi hollow sebesar $117 \mathrm{~N}$, sedangkan nilai gaya gesek kinetis $\left(f_{k}\right)$ yaitu sebesar 54,8 N. Untuk asumsi Durasi rentang waktu keseluruhan proses yang di butuhkan untuk mengubah posisi pompa dari rangkaian paralel menjadi rangkaian seri atau sebalik nya yaitu 8,5 menit.
\end{abstract}

Kata kunci: Pompa, Rangkaian, Rekayasa, Seat, Sliding.

\section{PENDAHULUAN}

Pengembangan teknologi pengujian pompa air dalam laboratorium diperlukan dalam mendukung kemajuan teknologi, khususnya dalam bidang teknologi perpompaan. Alat - alat uji praktikum dituntut memiliki efektifitas tinggi serta kemampuan yang teruji baik dalam memberikan data akurat untuk para peneliti. Alat uji praktikum pompa air pada umumnya tersusun secara permanen dan dirancang dengan kebutuhan dasar pengambilan data fluida [1]. Suatu alat yang menyebabkan perubahan energi antara suatu sistem mekanik dan media fluida disebut mesin fluida. Sedangkan mesin yang digerakan secara mekanik untuk melakukan kerja pada sistem fluida dan kemudian merubah energi mekanik menjadi energi fluida disebut pompa [2].

Dalam pengoprasian pompa, susunan rangkaian pemopaan bervariasi ada yang dipasang secara rangkaian seri dan ada juga yang secara rangkaian paralel. Tingkat fleksibilitas yang terbatas memberikan dampak bahwa data - data yang diambil dari alat laboratorium seringnya menjadi data awal yang perlu diolah lebih lanjut. Artinya pengembangan dan perancangan ulang (redesign) perlu dilakuakan agar alat - alat uji praktikum memiliki efektifitas tinggi serta kemampuan yang teruji dengan baik dalam memberikan data yang akurat. Tujuan dari penelitian ini adalah mengetahui metode yang akan digunakan dan memberi 
penjelasan prinsip kerja untuk perancangan ulang yg akan dilakukan. Serta memahami dan mengerti tentang karakteristik pompa susunan seri dan paralalel. Komponen utama dalam penelitian ini yaitu bearing, ulir daya, rel besi hollow.

\section{TINJAUAN PUSTAKA}

\section{Bearing}

Bearing adalah salah satu elemen mesin yang berfungsi untuk menumpu secara langsung bagian mesin yang bergerak atau berputar, misalnya as, poros, roda gigi dan sebagainya. Pemasangan bantalan dimaksudkan untuk menghindari kontak langsung antara bagian-bagian yang bergerak agar keausan terjadi hanya pada bantalannya [3]. Secara umum bearing dapat diklasifikasikan berdasarkan arah beban dan berdasarkan konstruksi atau mekanismenya mengatasi gesekan dan berdasarkan gerakannya terhadap poros yaitu:

1. Sliding contact bearing (bantalan luncur)

Pada bantalan ini terjadi gesekan luncur antara poros dan bantalan karena permukaan poros ditumpu oleh permukaan bantalan dengan perantaraan lapisan pelumas. Bantalan ini menggunakan mekanisme Sliding, diantara dua permukaan komponen mesin yang saling bergesekan.

2. Rolling contact / anti friction bearing (bantalan gelinding)

Pada bantalan ini terjadi gesekan gelinding antara bagian yang berputar dengan yang diam melalui elemen gelinding seperti bola, rol, dan rol bulat. Bantalan gelinding menggunakan elemen rolling untuk mengatasi gesekan antara dua komponen yang bergerak.

Kode bearing tersebut terdiri dari beberapa komponen yang dapat dibagibagi antara lain [3]. Contoh 6203 RS :

6 = melambangkan tipe /jenis bearing

2 = melambangkan seri bearing. $\mathbf{0 3}=$ melambangkan diameter lubang dalam bearing.

$\mathbf{R S}=$ melambangkan jenis bahan penutup bearing.

Tabel 1. Data Tipe Ball Bearing Seri 62 [4]

\begin{tabular}{|c|c|c|c|c|c|c|c|c|c|c|}
\hline \multirow[t]{2}{*}{$\begin{array}{l}\text { Nomor } \\
\text { Bearing }\end{array}$} & \multicolumn{2}{|c|}{$d$} & \multicolumn{2}{|c|}{ D } & \multicolumn{2}{|c|}{ B } & $r^{*}$ & $\begin{array}{l}\text { Berat } \\
\text { Bearing }\end{array}$ & $\begin{array}{l}\text { Basic } \\
\text { Static } \\
\text { Load } \\
\text { Rating }\end{array}$ & $\begin{array}{l}\text { Basic } \\
\text { Dynamic } \\
\text { Load } \\
\text { Rating }\end{array}$ \\
\hline & $\mathrm{mm}$ & in & $\mathrm{mm}$ & in & $\mathrm{mm}$ & in & in & $\mathrm{lb}$ & $\mathrm{lb}$ & $\mathrm{lb}$ \\
\hline 6200 & 10 & 0,3937 & 30 & 1,1811 & 9 & 0,3543 & 0,024 & 0,07 & 520 & 885 \\
\hline 6201 & 12 & 0,4724 & 32 & 1,2598 & 10 & 0,3937 & 0,024 & 0,08 & 675 & 1180 \\
\hline 6202 & 15 & 0,5906 & 35 & 1,378 & 11 & 0,4331 & 0,024 & 0,1 & 790 & 1320 \\
\hline 6203 & 17 & 0,6693 & 40 & 1,5748 & 12 & 0,4724 & 0,024 & 0,14 & 1010 & 1660 \\
\hline 6204 & 20 & 0,7874 & 47 & 1,8504 & 14 & 0,5512 & 0,039 & 0,23 & 1400 & 2210 \\
\hline 6205 & 25 & 0,9843 & 52 & 2,0472 & 15 & 0,5906 & 0,039 & 0,29 & 1610 & 2430 \\
\hline
\end{tabular}

Tabel 2. Faktor - faktor V, X dan Y Pada Bearing [3]

\begin{tabular}{|c|c|c|c|c|c|c|}
\hline \multirow[t]{2}{*}{ Tipe Bantalan } & \multirow[t]{2}{*}{$\frac{F_{a}}{C_{0}}$} & $\begin{array}{c}\text { Beban Putaran } \\
\text { Pada Cicin } \\
\text { Bearing Bagian } \\
\text { Dalam }\end{array}$ & $\begin{array}{c}\text { Beban Putaran } \\
\text { Pada Cicin } \\
\text { Bearing Bagian } \\
\text { Luar }\end{array}$ & \multicolumn{2}{|c|}{ Single Row Bearing } & \multirow[t]{2}{*}{$\mathrm{e}$} \\
\hline & & & V & $X$ & $\mathrm{Y}$ & \\
\hline \multirow{9}{*}{$\begin{array}{c}\text { Radial Contact } \\
\text { Groove Ball } \\
\text { Bearing }\end{array}$} & 0,014 & \multirow{9}{*}{1} & \multirow{9}{*}{1,2} & \multirow{9}{*}{0,56} & 2,3 & 0,19 \\
\hline & 0,028 & & & & 1,99 & 0,22 \\
\hline & 0,056 & & & & 1,71 & 0,26 \\
\hline & 0,084 & & & & 1,55 & 0,28 \\
\hline & 0,11 & & & & 1,45 & 0,3 \\
\hline & 0,17 & & & & 1,31 & 0,34 \\
\hline & 0,28 & & & & 1,15 & 0,38 \\
\hline & 0,42 & & & & 1,04 & 0,42 \\
\hline & 0,56 & & & & 1 & 0,44 \\
\hline
\end{tabular}

Ulir Daya

Dalam teknik mesin, ulir dibedakan menjadi dua kelompok menurut fungsinya, yaitu ulir pengikat (Threaded fasteners) dan ulir daya (Power screws). Ulir pengikat berfungsi untuk menyambung atau mengikat antara dua elemen, contohnya berbagai macam baut. Ulir daya berfungsi untuk mendapatkan keuntungan mekanik yang besar, biasanya diterapkan pada dongkrak ulir, klem, mesin pres, ragum, dan sebagainya. Jika membahas ulir, biasanya dikenal istilah pitch dan kisar (lead). Pitch adalah jarak antara puncak dengan puncak, sedangkan kisar adalah jarak yang ditempuh mur bila ulir diputar satu putaran. Dilihat dari banyaknya ulir tiap gang (pitch) maka ulir dapat di bedakan menjadi ulir tunggal dan ulir 
ganda. Ulir ganda artinya dalam satu putaran (dari puncak ulir yang satu ke puncak ulir yang lain) terdapat lebih dari satu ulir, misalnya dua ulir, tiga ulir dan empat ulir [5].

Melihat dari sisi ulir maka ulir dapat dibedakan menjadi ulir segi tiga, segi empat, trapesium, bulat dan tanduk. Selain itu juga dikenal jenis ulir berdasarkan posisi ulirnya yaitu ulir luar dan ulir dalam. Ulir luar adalah ulir yang posisinya pada diameter luar poros. Contoh aplikasi ulir luar ini adalah semua jenis baut dengan berbagai macamnya. Sedangkan ulir dalam adalah ulir yang posisinya pada diameter dalam / lubang sutau poros. Contoh aplikasi ulir dalam ini adalah semua jenis mur pengikat dengan berbagai macamnya [6].

1. Ulir segitiga : lebih cocok untuk digunakan untuk menyambung atau mengikat bagian / komponen mesin yang membubutuhkan kerapatan.

2. 2. Ulir Segi Empat / Square Thread: Merupakan ulir dengan bentuk profil segi empat, biasanya digunakan untuk beban berat misalnya pada pembuka pintu air bendungan dan ulir pada tanggem.

3. Ulir Trapesium / Trapezium Thread: Merupakan ulir dengan profil trapesium dengan sudut puncak $29^{\circ}$ $30^{\circ}$. biasa digunakan pada ulir penggerak pada eretan dan leadscrew pada mesin bubut.

4. Ulir Bulat / Round Thread : Merupakan ulir dengan profil setengah lingkaran pada bagian lembah dan puncak ulir. Biasa digunakan untuk mentranmisikan daya / gerakan secara halus dengan tanpa kelonggaran.

5. Ulir Tanduk / Buttress Thread : Merupakan ulir berbentuk segitiga tetapi bukan segitiga sama kaki melainkan berbentuk seperti tanduk.

\section{Rel Besi Hollow}

Besi hollow merupakan besi yang berbentuk kotak (persegi maupun persegi panjang) dengan tebal dan panjang yang bervariasi. Besi hollow menjadi besi yang cukup populer pada saat ini karena fungsinya yang cukup banyak dan beragam. Mulai dari kanopi, pintu pagar, pagar, pintu besi, railing, teralis minimalis modern, sebagai salah satu komponen utamanya. Jenis besi hollow yang sering di jumpai di pasaran [7].

1. Besi Hollow Galvanise : Besi ini merupakan sebutan untuk pelapisan finishing yang terdiri dari $97 \%$ unsur coating zinc ( besi ), $\pm 1 \%$ unsur coating alumunium dan sisanya adalah unsur bahan lain. Dengan komposisi bahan seperti ini, akan membuat besi hollow jenis ini menjadi korosif, terlebih lagi jika besi ini tergesek maupun terpotong.

2. Besi Hollow Galvalume : Merupakan sebutan untuk Zinc - Alume yang pelapisannya mengandung unsur Alume (Aluminium) dan Zinc (besi). Untuk bahan Galvalume yang paling baik terdiri dari unsur coatingnya 55\% Aluminium, unsur besi $43,5 \%$ dan unsur lapisan silicon $1,5 \%$. Dilihat dari komposisi bahannya besi hollow galvalume ini memiliki ketahanan yang baik terhadap korosi, otomatis harga lebih mahal dari besi hollow galvanise.

\section{METODE PENELITIAN}

Penelitian ini dilakukan dengan 3 tahapan:

1. Pemodelan desain menggunakan software solidworks,

2. Perancangan dan perhitungan,

3. Pengujian.

Pemodelan desain ditunjukkan pada gambar 1 menggunakan software solidworks dengan mengaplikasi mekanisme: Bantalan gelinding atau bearing, Ulir daya (Power Screw), dan Rel besi hollow. 


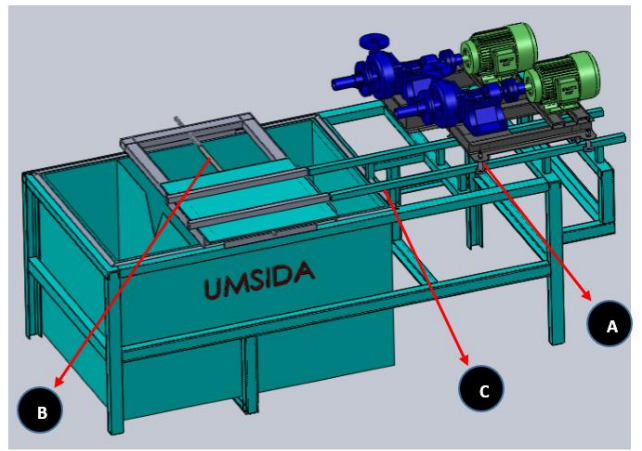

Keterangan:

$$
\begin{aligned}
& \mathrm{A}=\text { Bantalan gelinding atau bearing. } \\
& \mathrm{B}=\text { Ulir daya (Power Screw). } \\
& \mathrm{C}=\text { Rel besi hollow. }
\end{aligned}
$$

Gambar 1. Desain Sliding Pompa Software Solidworks

\section{HASIL DAN PEMBAHASAN}

\section{Perancangan Dan Perhitungan Bearing}

Jenis bearing yang cocok untuk penelitian ini (sebagai roda) adalah bearing dengan kode 6203 dengan spesifikasi:

Tabel 3. Spesifikasi Prancangan Bearing

\begin{tabular}{|c|c|c|}
\hline No & Spesifikasi & $\begin{array}{c}\text { Nilai atau } \\
\text { Keterangan }\end{array}$ \\
\hline 1 & Tipe & $\begin{array}{c}\text { Single Row Deep } \\
\text { Groove Ball Bearing }\end{array}$ \\
\hline 2 & Kode & 6203 \\
\hline 3 & $D$ & $40 \mathrm{~mm}$ \\
\hline 4 & $d$ & $17 \mathrm{~mm}$ \\
\hline 5 & $B$ & $12 \mathrm{~mm}$ \\
\hline 6 & $C$ & $1660 \mathrm{lb}$ \\
\hline 7 & $C_{o}$ & $1010 \mathrm{lb}$ \\
\hline
\end{tabular}

Keterangan :

$D=$ Diameter dalam

$D=$ Diameter luar

$B=$ Lebar bearing

$C=$ Basic Dynamic Load Rating

$C_{o}=$ Basic Static Load Rating

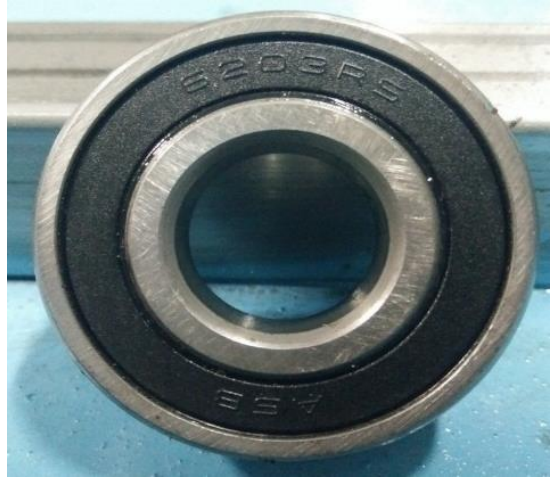

Gambar 2. Bearing 6203
Prosedur perhitungan umur bearing sebagai pengganti roda :

1. Langkah pertama $=$ menentukan nilai faktor beban X dan Y [3].

$$
\frac{F_{a}}{V \cdot F_{r}} \leq e
$$

Dengan:

- $\mathrm{F}_{\mathrm{a}}($ Beban aksial konstan yang bekerja $)=$ $0 \mathrm{~kg}$ (Tidak ada beban aksial yang bekerja pada bearing)

- $\mathrm{F}_{\mathrm{r}}($ Beban radial konstan yang bekerja $)=$ $80 \mathrm{~kg}$ atau sama dengan $784 \mathrm{~N}$

- $\mathrm{V}$ (Faktor perputaran) $=1,2$ (Nilai bearing bagian luar yang berputar, terdapat pada Tabel 2)

- $e($ Nilai faktor beban $)=($ Terdapat pada Tabel 2)

Keterangan: $1 \mathrm{~kg}=9,8 \mathrm{~N}$

$$
\begin{gathered}
\frac{F_{a}}{V \cdot F_{r}} \leq e \\
\frac{0}{1,2 \cdot 784} \leq e \\
0 \leq e
\end{gathered}
$$

Didapatkan nilai faktor $\mathrm{X}=1$ dan $\mathrm{Y}=0$.

2. Langkah kedua $=$ menghitung $P$ (Beban ekuivalen) yang bekerja pada pada bantalan [3].

$$
P=X V F_{r}+Y F_{a}
$$

Dengan:

- $F_{r}($ Beban radial konstan yang bekerja $)=$ $784 \mathrm{~N}$

- $F_{a}$ Beban aksial konstan yang bekerja) $=$ 0 N (Tidak ada beban aksial yang bekerja pada bearing)

- $V$ (Faktor perputaran) = 1,2 (Karena bearing bagian luar yang berputar, terdapat pada Tabel 2)

- $X($ Faktor radial $)=1$

- $Y($ Faktor aksial $)=0$

- $P$ (Beban ekuivalen) = (Belum diketahui) 


$$
\begin{aligned}
& P=X V F_{a}+Y F_{r} \\
& P=1.1,2 \cdot 784+0.0 \\
& P=940 \mathrm{~N}
\end{aligned}
$$

Diperoleh nilai $P$ (Beban ekuivalen) sebesar $940 \mathrm{~N}$ yang bekerja pada bantalan.

3. Langkah ketiga $=$ menentukan nilai $L_{10}$ = Umur putaran bantalan / bearing [3].

$$
L_{10}=\left(\frac{C}{P}\right)^{3}
$$

Dengan:

- $\quad$ (Basic Dynamic Load Rating) $=1660$ lb atau sama dengan $7384 \mathrm{~N}$ (Bantalan dengan tipe 6203 pada Tabel 1)

- $P($ Beban ekuivalen $)=940 \mathrm{~N}$

- $L_{10}($ Umur putaran bantalan $/$ bearing $)=$ (Belum diketahui)

Keterangan: $1 \mathrm{lb}=4,45 \mathrm{~N}$

$$
\begin{aligned}
& L_{10}=\left(\frac{C}{P}\right)^{3} \\
& L_{10}=\left(\frac{7384}{940}\right)^{3} \\
& L_{10}=474,5 \text { juta putaran. }
\end{aligned}
$$

Didapatkan kesimpulan bearing kode 6203 menumpu beban ekuivalen sebesar $940 \mathrm{~N}$ dan dapat berputar sebanyak 474,5 juta putaran dengan keandalan $90 \%$.

\section{Perancangan dan Perhitungan Ulir Daya}

Mekanisme ulir daya yang digunakan dalam penelitian ini adalah ulir daya jenis persegi empat yang memiliki panjang 1 meter. Spesifikasi perancangan ulir daya dalam penelitian ini yaitu :

Tabel 4. Spesifikasi Perancangan Ulir Daya

\begin{tabular}{|c|c|c|}
\hline No & Spesifikasi & $\begin{array}{c}\text { Nilai atau } \\
\text { Keterangan }\end{array}$ \\
\hline 1 & Jenis & Ulir Persegi Empat \\
\hline 2 & $d$ & $16 \mathrm{~mm}$ \\
\hline 3 & $p$ & $2 \mathrm{~mm}$ \\
\hline 4 & Panjang & $1000 \mathrm{~mm}$ \\
\hline
\end{tabular}

Keterangan :

$d=$ Diameter rata - rata colar $p=$ Pitch

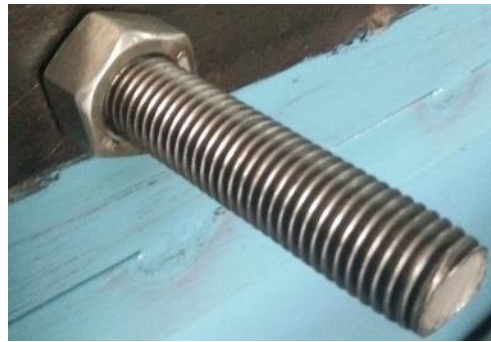

Gambar 3. Ulir Daya Persegi Empat

Prosedur perhitungan Torsi yang dibutuhkan untuk memutar ulir daya berbeban :

1. Langkah pertama $=$ menentukan lebar dan tinggi ulir.

$$
d_{p}=d-\frac{p}{2}
$$

Dengan:

- $p($ pitch $)=2 \mathrm{~mm}$

- $d$ (Diameter rata - rata colar $)=16 \mathrm{~mm}$

- $d_{p}$ (Diameter kedalaman ulir $)=($ Belum diketahui)

$$
\begin{aligned}
& d_{p}=d-\frac{p}{2} \\
& d_{p}=16-\frac{2}{2} \\
& d_{p}=15 \mathrm{~mm}
\end{aligned}
$$

Didapatkan nilai $d_{p}=15 \mathrm{~mm}$.

2. Langkah kedua $=$ mentukan kisar

$$
l=2 \cdot p
$$

Dengan:

- $p($ pitch $)=2 \mathrm{~mm}$

- $l($ lead atau kisar $)=($ Belum diketahui $)$

$$
\begin{aligned}
& l=2 \cdot p \\
& l=2.2 \\
& l=4 \mathrm{~mm}
\end{aligned}
$$

Diperoleh nilai $l=4 \mathrm{~mm}$.

3. Langkah ketiga $=$ menghitung Torsi [5]. 


$$
T=\frac{P d_{p}}{2}\left(\frac{l+\pi \mu d_{p}}{\pi d_{p-\mu l}}\right)+\frac{P \mu_{c} d}{2}
$$

Dengan:

- $P($ Beban yang di tumpu $)=784 \mathrm{~N}$

- $d$ (Diameter rata - rata colar $)=16 \mathrm{~mm}$

- $d_{p}$ (Diameter kedalaman ulir $)=15 \mathrm{~mm}$ (Hasil Persamaan 3.1)

- $l$ (lead kisar $)=4 \mathrm{~mm}$ (Hasil persamaan 3.2)

- $\mu$ (Koefisien gesek ulir $)=0,08$

- $\mu c$ (Koefisien gesek pada colar $)=0,08$

- T (Torsi yang digunakan untuk memutar ulir daya $)=($ Belum diketahui $)$

$$
\begin{aligned}
T= & \frac{P d_{p}}{2}\left(\frac{l+\pi \mu d_{p}}{\pi d_{p-\mu l}}\right)+\frac{P \mu_{c} d}{2} \\
T= & \frac{0,7 \cdot 15}{2}\left(\frac{4+\pi 0,08 \cdot 15}{\pi 15+0,08 \cdot 4}\right)+ \\
& \frac{784 \cdot 0.08 \cdot 16}{2}
\end{aligned}
$$

$$
T=503 \mathrm{Nm}
$$

Didapatkan kesimpulan bahwa di butuhkan Torsi sebesar $503 \mathrm{Nm}$ untuk memutar ulir daya dengan beban $784 \mathrm{~N}$.

\section{Perancangan dan Perhitungan Rel Besi Hollow}

Pada penelitian ini perancangan rel menggunakan 2 batang besi hollow galvanise dengan ukuran panjang masing -

\begin{tabular}{|c|c|c|}
\hline No & Spesifikasi & $\begin{array}{c}\text { Nilai atau } \\
\text { Keterangan }\end{array}$ \\
\hline 1 & Jenis & Galvanise \\
\hline 2 & Panjang & $1040 \mathrm{~mm}$ \\
\hline 3 & Tinggi & $25 \mathrm{~mm}$ \\
\hline 4 & Lebar & $25 \mathrm{~mm}$ \\
\hline 5 & Tebal & $1,6 \mathrm{~mm}$ \\
\hline
\end{tabular}
masing $104 \mathrm{~cm}$. Spesifikasi perancangan rel besi hollow dalam penelitian ini yaitu :

Tabel 5. Spesifikasi Perancangan rel besi hollow

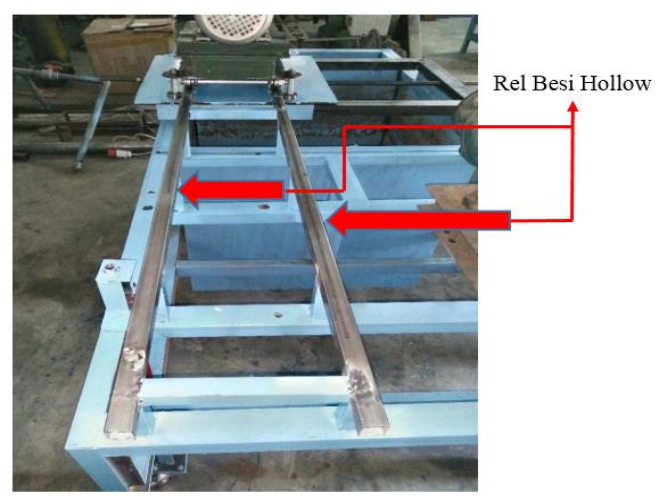

Gambar 4. Rel Besi Hollow

Prosedur perhitungan gaya gesek besi hollow yang di fungsikan sebagai rel (landasan bearing).

1. Langkah pertama $=$ menentukan nilai gaya gesek statis $\left(f_{s}\right)$ [8].

$$
f_{s}=\mu_{s} . N
$$

Dengan:

- $\mu_{s}($ Koefisien gaya gesek statis $)=0,15$ [9]

- $N$ (Gaya normal $)=784 \mathrm{~N}$

- $f_{s}$ (Gaya gesek statis $)=($ Belum diketahui)

$$
\begin{gathered}
f_{s}=\mu_{\mathrm{s} . \mathrm{N}} \\
f_{s}=0,15.784 \\
f_{s}=117 \mathrm{~N}
\end{gathered}
$$

Didapatkan $f_{s}=117 \mathrm{~N}$.

2. Langkah kedua $=$ menentukan nilai gaya gesek kinetis $\left(f_{k}\right)$ [8].

$$
f_{k}=\mu_{\mathrm{k}} . \mathrm{N}
$$

Dengan:

- $\mu_{k}$ (Koefisien gaya gesek kinetis $)=0,07$ [9]

- $N($ Gaya normal $)=784 \mathrm{~N}$

- $f_{k}$ (Gaya gesek kinetis $)=($ Belum diketahui)

$$
f_{k}=\mu_{\mathrm{s}} . \mathrm{N}
$$




$$
\begin{gathered}
f_{k}=0,07.784 \\
f_{k}=54,8 \mathrm{~N}
\end{gathered}
$$

Diperoleh $f_{k}=54,8 \mathrm{~N}$.

Didapatkan kesimpulan bahwa besi hollow menumpu beban $784 \mathrm{~N}$ dengan bearing yang berfungsi sebagai roda memiliki nilai gaya gesek statis $\left(f_{s}\right)$ sebesar 117 N. Sedangkan nilai gaya gesek kinetis $\left(f_{k}\right)$ yaitu sebesar $54,8 \mathrm{~N}$.

\section{Pengujian}

Pengujian pada penelitian ini dilakukan dengan 2 metode yaitu :

1. Posisi pompa rangkaian seri

2. Posisi pompa rangkaian pralel

\section{Posisi Pompa Rangkaian Seri}

Asusmi saat ini posisi Pompa 1 dan Pompa 2 dalam rangkaian pompa paralel seperti yang ditunjukkan pada gambar 5, gambar 6, gambar 7 dan gambar 8. Pompa 2 di dorong secara manual dari Titik A sampai pada titik B, Seperti yang ditunjukan pada gambar 9 .

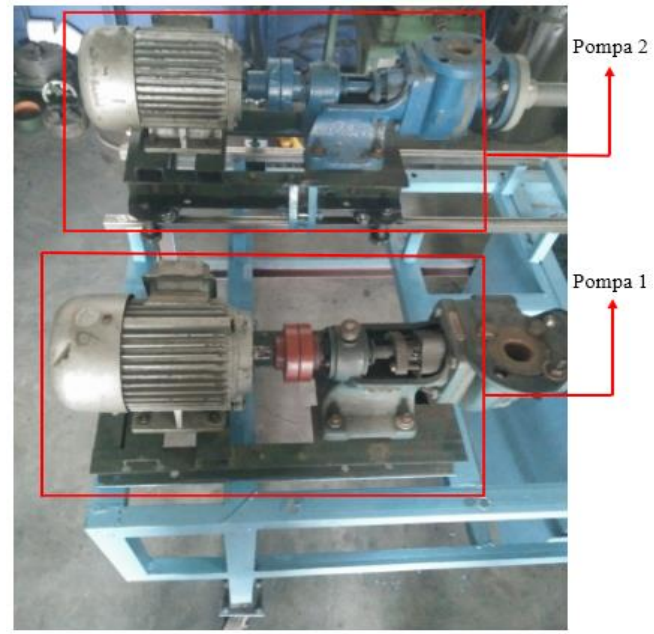

Gambar 5. Posisi Pompa Rangkaian Parelel Sudut Pandang Sisi Kanan

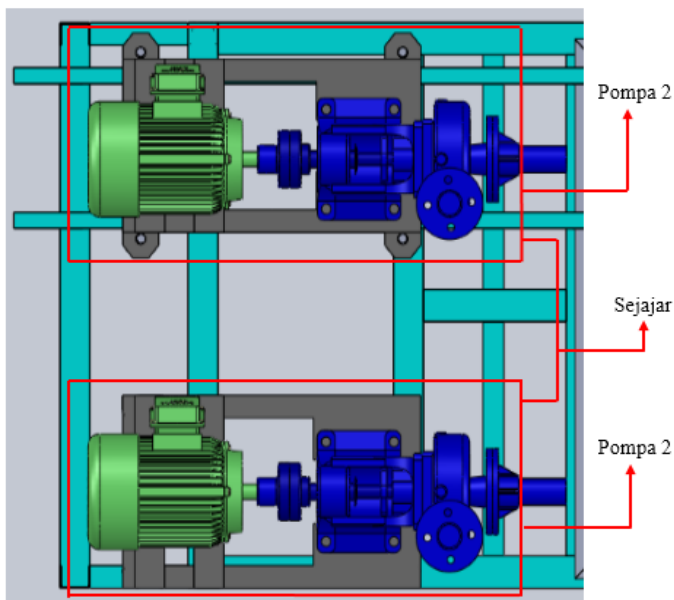

Gambar 6. Posisi Pompa Rangkaian Parelel (Sejajar) Software Solidworks

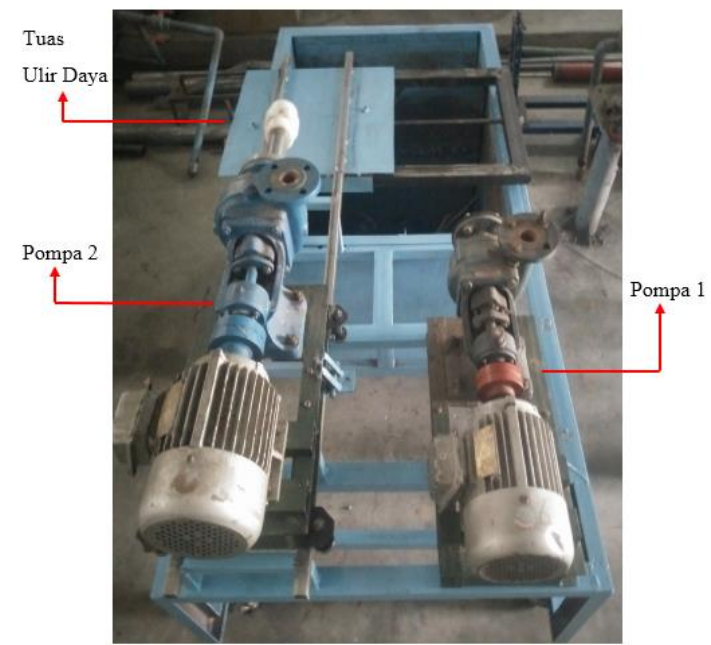

Gambar 7. Posisi Pompa Rangkaian Paralel Sudut Pandang Sisi Belakang

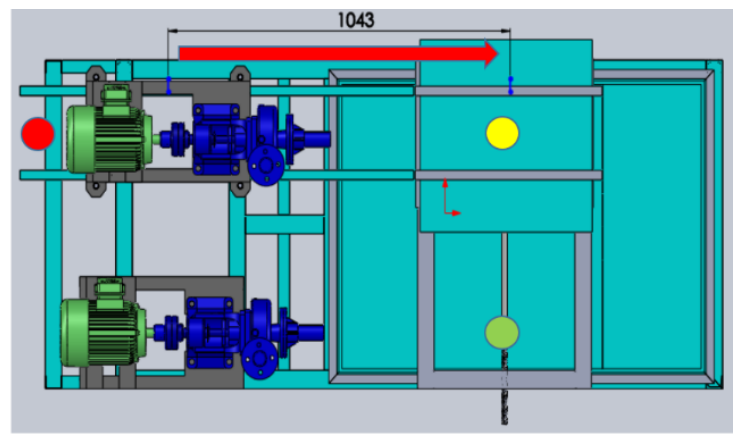

Gambar 8. Posisi Pompa Rangkaian Paralel Dari Sudut Pandang Sisi Atas Software Solidworks 


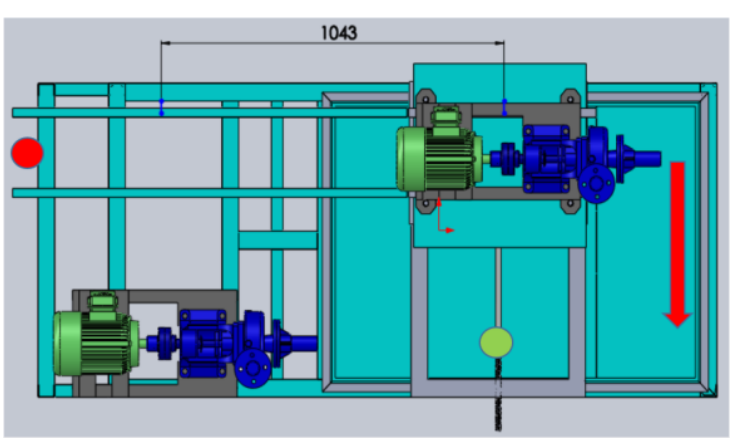

Gambar 9. Jarak Yang Ditempuh Dari Titik A ke Titik B (1043 mm) Software Solidworks

Keterangan :

= Lingkaran berwarna merah menunjukan Titik A

= Lingkaran berwarna kuning menunjukan Titik B

= Lingkaran berwarna hijau menunjukan Titik C

Langkah selanjunya yaitu memutar ulir daya malawan jarum jam secara otomatis Pompa 2 akan berpindah dari Titik $\mathrm{B}$ menuju Titik $\mathrm{C}$ dengan jarak yang di tempuh $500 \mathrm{~mm}$ seperti yang di tunjukan pada gambar 10 dan gambar 11 .

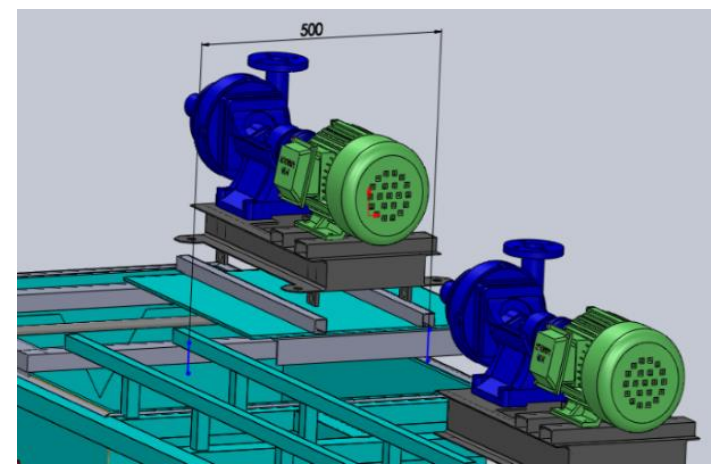

Gambar 10. Jarak Tempuh Ulir Daya (500 $\mathrm{mm}$ ) Software Solidworks

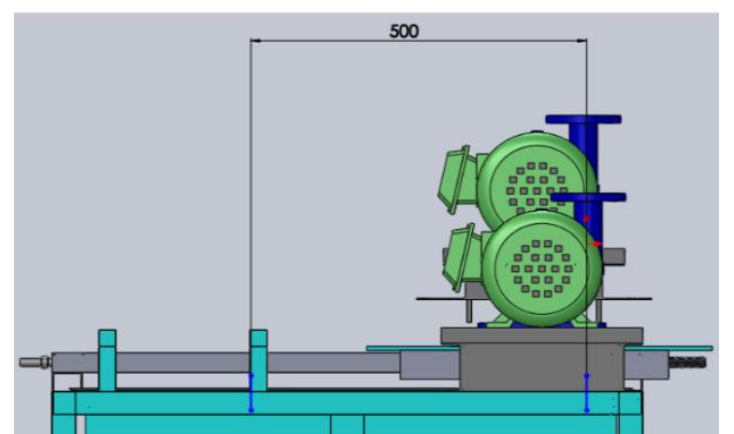

Gambar 11. Ukuran Jarak Tempuh Ulir Daya Dari Sisi Belakang (500 mm) Software Solidworks
Maka jadilah posisi rangkaian pompa seri yang, yaitu Pompa 2 dan Pompa 1 menjadi sebaris atau lurus seperti yang terlihat pada gambar 12 dan gambar 13.

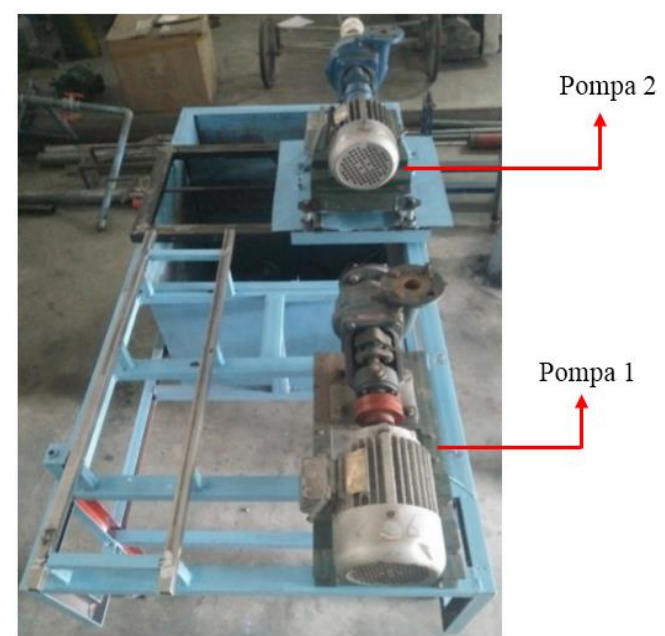

Gambar 12. Posisi Pompa Rangkaian Seri Dari Sudut Pandang Sisi Atas

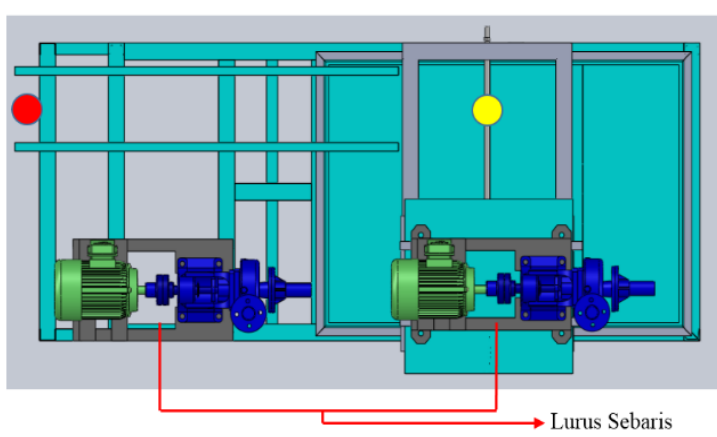

Gambar 13. Posisi Pompa Rangkaian Seri Dari Sudut Pandang Sisi Atas Software Solidworks

Asumsikan total rentang waktu keseluruhan proses yang di butuhkan untuk mengubah posisi pompa dari rangkaian paralel menjadi rangkaian seri yaitu, total waktu perpindahan dari Titik A ke Titik B (133 detik) di jumlahkan dengan total waktu perpindahan dari Titik B ke Titik C (380 detik) maka hasil yang di dapat adalah 513 detik $=8,5$ menit.

\section{Posisi Pompa Rangkaian Paralel}

Asumsi saat ini posisi Pompa 1 dan Pompa 2 sebaris atau dalam rangkaian pompa seri seperti yang ditunjukan pada gambar 12 dan gambar 13. Apa bila akan memindah posisi pompa menjadi rangkain paralel, maka posisi Pompa 2 harus di pindah dari Titik C menuju Titik A 
melewati Titik B. Langkah awal memutar ulir daya searah jarum jam secara otomatis posisi Pompa 2 yang tadinya berada pada Titik C akan berpindah ke Titik B. Langkah selanjutnya mendorong secara manual Pompa 2 menuju Titik A. Maka jadilah rangkaian pompa paralel dengan posisi Pompa 1 dan 2 sejajar seperti yang di tunjukan pada gambar 5, gambar 6 gambar 7 dan gambar 8.

Asumsi waktu yang di butuhkan untuk merubah posisi pompa dari rangkaian seri menjadi rangkaian paralel adalah sama dengan asumsi waktu yang di butuhkan untuk merubah posisi pompa dari rangkaian paralel menjadi rangkaian seri.

\section{KESIMPULAN}

1. Komponen Utama Penelitian ini yaitu :

- Bearing dengan kode 6203 sebagai penggati roda.

- Ulir daya persegi empat sebagai media perpindahan posisi pompa.

- Rel besi hollow galvanise sebagai lintasan bearing.

2. Proses penggantian rangkain pompa seri ke pompa paralel atau pun sebaliknya tidak perlu membongkar dudukan pompa yang ada.

3. Durasi rentang waktu keseluruhan proses yang di butuhkan untuk mengubah posisi pompa dari rangkaian paralel menjadi rangkaian seri atau sebalik nya yaitu 8,5 menit.

\section{REFERENSI}

[1]. R. Y. Pradhana and E. Widodo, "Analisa Pengaruh Variasi Diameter Pipa Tekan Pvc Pada Pompa Aksial Untuk Kecepatan Gaya Dorong Air," $R$ E.M. (Rekayasa Energi Manufaktur) J., vol. 2, no. 1, pp. 37-43, 2017.

[2]. Nasirwan, "Optimasi pengujian pompa seri dan paralel," Mech. Eng., vol. Politeknik, p. Padang, 2008. Nasirwan, "Optimasi pengujian pompa seri dan paralel," Mech. Eng., vol. Politeknik, p. Padang, 2008.

[3]. Sularso, "Dasar Perencanaan dan Pemilihan Elemen Mesin," 2004

[4]. R. L . Mott, "Machine Elements in Mechanical Design," 2nd Ed., vol. Macmillan, 1992.

[5]. Joseph, "Mechanical Engineering Design," 2001.

[6]. P. I. Ahamd Nur Rokman, Muhammad Faizal S, "Metrologi Industri Metrologi Ulir." 2011.

[7]. PT., "Beberapa Jenis Besi Hollow Yang Perlu Anda Ketahui," p. 55, 2016.

[8]. David, "Fisika Jilid 1,” 1987.

[9]. A. P. Arya, "Introduction Classical Mechanics," 1998. 